\title{
Discovery of Novel 4-Arylisochromenes as Anticancer Agents Inhibiting Tubulin Polymerization
}

\author{
Wenlong Li, ${ }^{\dagger}$ Wen Shuai, ${ }^{\dagger}$ Feijie $\mathrm{Xu},{ }^{\dagger}$ Honghao Sun,${ }^{\dagger}$ Shengtao $\mathrm{Xu},{ }^{*}{ }^{\dagger}$ Hong Yao, ${ }^{\dagger}$ Jie Liu, ${ }^{*,+}$ \\ Hequan Yao, Zheying Zhu, ${ }^{\S}$ and Jinyi $\mathrm{Xu}^{*}{ }^{*}+0$ \\ ${ }^{\dagger}$ Department of Medicinal Chemistry and State Key Laboratory of Natural Medicines, China Pharmaceutical University, \\ 24 Tong Jia Xiang, Nanjing 210009, P. R. China \\ ${ }^{\ddagger}$ Department of Organic Chemistry, China Pharmaceutical University, 24 Tong Jia Xiang, Nanjing 210009, P. R. China \\ ${ }^{\S}$ Division of Molecular Therapeutics \& Formulation, School of Pharmacy, The University of Nottingham, University Park Campus, \\ Nottingham NG7 2RD, U.K.
}

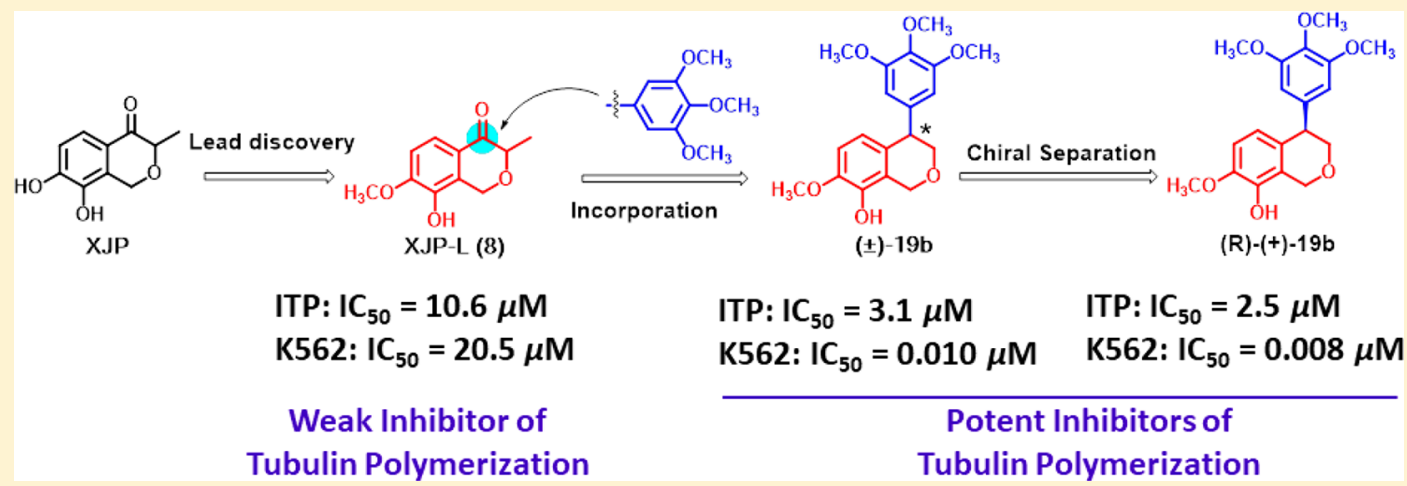

ABSTRACT: XJP-L (8), a derivative of the natural product ( \pm )-7,8-dihydroxy-3-methylisochroman-4-one isolated from the peel of Musa sapien tum L., was found to exhibit weak inhibitory activity of tubulin polymerization $\left(\mathrm{IC}_{50}=10.6 \mu \mathrm{M}\right)$ in our previous studies. Thus, a series of 4-arylisochromene derivatives were prepared by incorporating the trimethoxyphenyl moiety into 8 , among which compound $( \pm)-19 \mathrm{~b}$ was identified as the most potent compound with $\mathrm{IC}_{50}$ values ranging from 10 to $25 \mathrm{nM}$ against a panel of cancer cell lines. Further mechanism studies demonstrated that $( \pm)-19 b$ disrupted the intracellular microtubule network, caused G2/M phase arrest, induced cell apoptosis, and depolarized mitochondria of K562 cells. Moreover, $( \pm)-19 \mathrm{~b}$ exhibited potent in vitro antivascular and in vivo antitumor activities. Notably, the $R$-configured enantiomer of $( \pm)-19 b$, which was prepared by chiral separation, was slightly more potent than $( \pm)-19 b$ and was much more potent than the $S$-configured enantiomer in both antiproliferative and antitubulin assays. Our findings suggest that $( \pm)$-19b deserves further research as a potential antitubulin agent for the treatment of cancers.

KEYWORDS: Combretastatin A-4, ( \pm )-7,8-Dihydroxy-3-methylisochroman-4-one, Tubulin inhibitors, Enantioseparation, Antitumor, Vascular disrupting

\begin{abstract}
$\mathrm{C}$ ombretastatin A-4 (1, CA-4) (Figure 1), a natural cisstilbene derivative isolated from the bark of the African willow tree Combretum caffrum, ${ }^{1}$ was found to be a powerful inhibitor of tubulin polymerization targeting the colchicine binding site. ${ }^{2}$ CA-4 has strong cytotoxicity against a variety of tumor cells with a broad therapeutic window. Besides, CA-4 was reported to show vascular disrupting properties at a tolerated dose. ${ }^{3}$ The potent antimitotic and vascular disrupting profiles of CA-4 made it a promising therapy for the treatment of cancers. $^{4-7}$ However, CA-4P (2, Fosbretabulin), the phosphate prodrug of CA-4, had been discontinued in clinical trials $^{8}$ due to the lack of a meaningful improvement in progression-free survival (PFS) and unfavorable partial response data. ${ }^{9}$ In the presence of light, heat, or acid media, but also after in vivo administration, the $Z$-isomer of CA-4
\end{abstract}

easily isomerizes to the $E$-isomer that is significantly less potent at inhibiting tubulin polymerization and cancer cell growth. ${ }^{10}$ Strategies to surmount this drawback have been taken by modification on the bridge structure of CA-4, which lead to the discovery of various moieties replacing the cis-double bond. ${ }^{11-13}$ Fusing cis-olefin into the ring B represents an important tactic to lock the cis double bond; compounds 3-6 with highly potent cytotoxicity were thus discovered (Figure 1). ${ }^{14-21}$

It is known to all that natural products with structurally diverse frameworks have always been and continue to be an

Received: May 10, 2018

Accepted: September 25, 2018

Published: September 25, 2018 


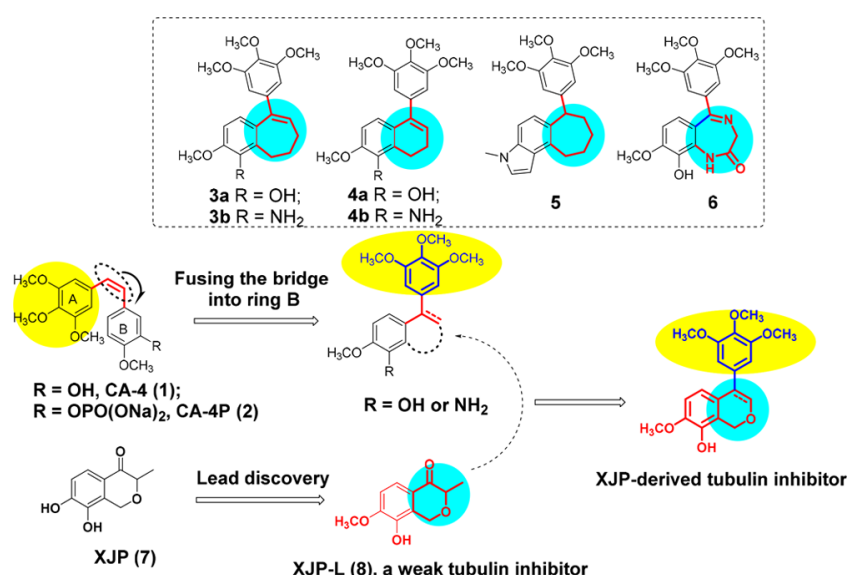

Figure 1. Strategy of fusing the bridge into ring B of CA-4 to surmount its instability and the design of XJP derived tubulin inhibitor.

important source for new drug discovery. ${ }^{22}$ ( \pm )-7,8-Dihydroxy-3-methylisochroman-4-one $[7,( \pm)$-XJP] was a structurally unique 4-isochromanone compound which was isolated from the peel of Musa sapientum L. and totally synthesized by our group, ${ }^{23,24}$ and it exhibited a wide range of favorable pharmacological properties. ${ }^{25,26}$ In our previous research for discovering new antitubulin agents with novel skeletons, a series of XJP derivatives was screened for their inhibitory activity of tubulin polymerization. Interestingly, XJP-L (8) was found to exhibit weak microtubule polymerization inhibitory activity $\left(\mathrm{IC}_{50}=10.6 \mu \mathrm{M}\right)$.

Considering the vital roles of 3,4,5-trimethoxyphenyl on the activity of inhibitors of tubulin polymerization targeting the colchicine binding site, ${ }^{27-29} \mathbf{8}$ was further hybridized with a 3,4,5-trimethoxyphenyl moiety for improving both its antiproliferative and inhibitory activities of tubulin polymerization using the cis-double bond locking strategy. Thus, a series of novel 4-arylisochromenes were designed and synthesized (Figure 1). Herein, we wish to report their synthesis and antitumor activities as antitubulin agents.

The synthetic route for the preparation of 4-arylisochromenes is outlined in Scheme 1. Various substituted XJP scaffolds 12a-e were synthesized according to the method utilizing a Parham-type cyclization with the tert-butyllithium reagent reported by our group. ${ }^{30}$ Sulfur-containing XJP scaffolds $\mathbf{1 2 f}-\mathbf{g}$ were further synthesized via a Friedel-Crafts cyclic reaction.

Then, $12 \mathbf{a}-\mathbf{g}$ were transformed into their corresponding $\mathrm{N}$-tosylhydrazones $15 \mathrm{a}-\mathrm{g}$ in refluxing $\mathrm{EtOH}$ with good to excellent yields, followed by the coupling of $15 \mathrm{a}-\mathrm{g}$ with 5-bromo-1,2,3-trimethoxybenzene (16) via a Pd-catalyzed cross-coupling to afford $17 \mathbf{a}-\mathrm{g}$ in moderate to good yields. Utilizing the different reducing capacities of $\mathrm{Pd}-\mathrm{C} / \mathrm{H}_{2}$ in THF and $\mathrm{CH}_{3} \mathrm{OH}$, the benzyl groups of $\mathbf{1 7 b}$ and $\mathbf{1 7} \mathbf{d}$ were selectively deprotected using THF as the solvent to give compounds $18 \mathrm{a}$ and $\mathbf{1 8 b}$, respectively, while double bonds were reduced to afford $( \pm)-19 a-d$ with $\mathrm{CH}_{3} \mathrm{OH}$ as the solvent.

All target compounds 17a, 17c, 17e-g, 18a-b, and $( \pm)-19 a-d$ were initially evaluated for their antiproliferative activities against human hepatocellular carcinoma cells (HepG2) by the MTT assays. Most of the synthesized compounds displayed potent activity against HepG2 cells, and the preliminary structure activity relationships (SARs) were obtained. The position of the hydroxyl group on the isochroman moiety was crucial for antiproliferative activity. Compounds $18 b$ and $( \pm)-19 b$, which contain hydroxyl at the
Scheme 1. Synthetic Route to 4-Arylisochromenes ${ }^{a}$

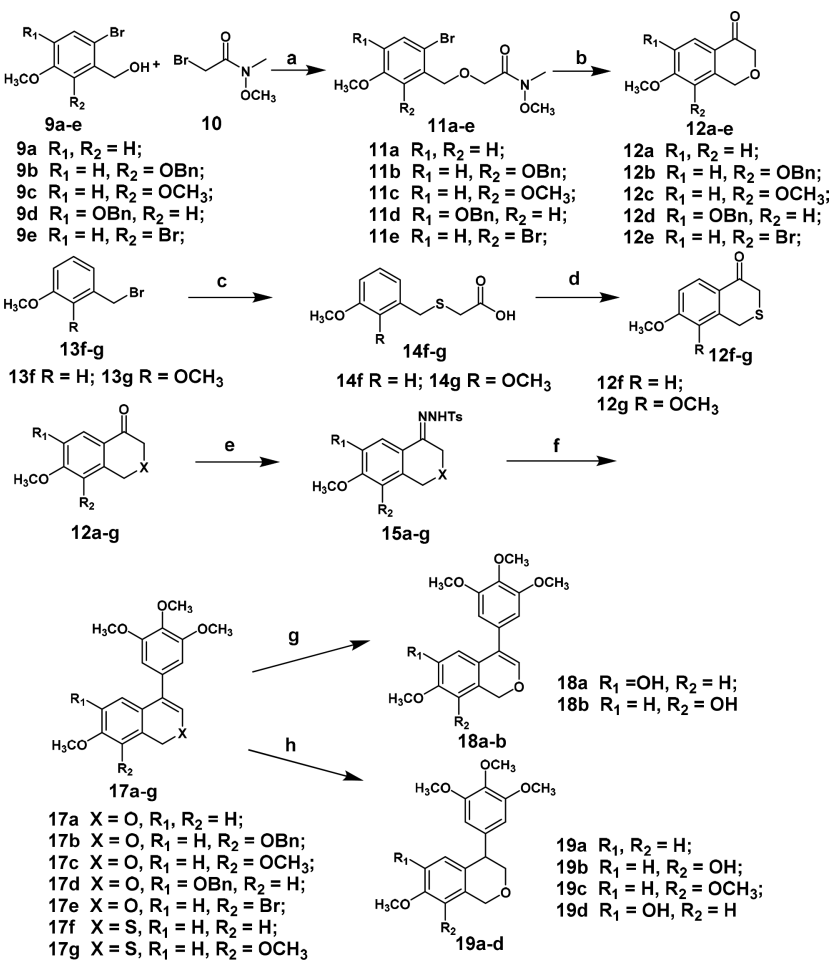

${ }^{a}$ Reagents and conditions: (a) NaH, DMF, $2 \mathrm{~h}, 55-70 \%$; (b) $t$-BuLi, THF, $-78{ }^{\circ} \mathrm{C}, 15 \mathrm{~min}, 72-90 \%$; (c) (i) ethyl thioglycolate, $\mathrm{K}_{2} \mathrm{CO}_{3}$, $\mathrm{CH}_{3} \mathrm{CN}, 2 \mathrm{~h}, 75-88 \%$; (ii) $10 \% \mathrm{NaOH}$ aqueous, $\mathrm{CH}_{3} \mathrm{OH}, 80{ }^{\circ} \mathrm{C}$, 85-90\%; (d) (i) oxalyl chloride, DMF(cat.), DCM; (ii) $\mathrm{SnCl}_{4}$, chlorobenzene, 55-65\% over two steps; (e) p-Toluenesulfonhydrazide, EtOH, $90{ }^{\circ} \mathrm{C}$, 75-90\%; (f) 5-bromo-1,2,3-trimethoxybenzene (16), $\mathrm{PdCl}_{2}\left(\mathrm{CH}_{3} \mathrm{CN}\right)_{2}$, Xphos, $t$-BuOLi, $90{ }^{\circ} \mathrm{C}, 45-70 \%$; (g) $\mathrm{Pd} / \mathrm{C}$, $\mathrm{H}_{2}$, THF, 65-92\%; (h) Pd/C, $\mathrm{H}_{2}, \mathrm{CH}_{3} \mathrm{OH}, 72-95 \%$.

C-5 position $\left(\mathrm{R}_{2}\right)$, exhibited the most potent activity with $\mathrm{IC}_{50}$ values of 26 and $15 \mathrm{nM}$, respectively. Moving the $\mathrm{OH}$ group from the $\mathrm{C}-5$ position to the $\mathrm{C}-3$ position led to the loss of antiproliferative activity $\left(\mathbf{1 8 a}\right.$ and $\left.\mathbf{1 9 d}, \mathrm{IC}_{50}>10 \mu \mathrm{M}\right)$. When $\mathrm{R}_{2}$ was substituted with other groups such as $\mathrm{OCH}_{3}[17 \mathrm{c}$ and $( \pm)-19 \mathrm{c}], \mathrm{Br}(17 \mathrm{e})$, or no substitution [17a and $( \pm)-19 \mathrm{a}]$, the activity significantly decreased when compared with $\mathbf{1 8 b}$ and $( \pm)-19 b$. Besides, the activity was maintained when sulfur $(\mathrm{X}=\mathrm{S})$ was introduced into the isochroman scaffold (17f and $17 \mathrm{~g}$ ). The reduction of double bonds led to a slight improvement of activity $[17 \mathrm{a}$ vs $19 \mathrm{a}, 17 \mathrm{c}$ vs $( \pm)-19 \mathrm{c}$, and $18 \mathrm{~b}$ vs $( \pm)-19 b]$. Especially, compound $( \pm)-19 b$ displayed the most potent antiproliferative activity $\left(\mathrm{IC}_{50}=15 \mathrm{nM}\right)$, which exhibited nearly 1000-fold improvement of activity toward 8 $\left(\mathrm{IC}_{50}=23.7 \mu \mathrm{M}\right)$ (See Supporting Information Table S1).

Subsequently, compounds $18 \mathrm{~b}$ and $( \pm)-19 b$ were further evaluated for their antiproliferative activity against another five cancer cell lines including KB, HCT-8, MDA-MB-231, K562, and $\mathrm{H} 22$ cells. As shown in Table 1 , both $\mathbf{1 8 b}$ and $( \pm)-\mathbf{1 9 b}$ showed potent antiproliferative activities. Especially, $( \pm)-19 \mathrm{~b}$ exhibited the most active against $\mathrm{K} 562$ cell lines with the $\mathrm{IC}_{50}$ value of $10 \mathrm{nM}$, which is more potent than the positive control CA-4 $\left(\mathrm{IC}_{50}=15 \mathrm{nM}\right)$; human normal hepatocytes LO2 cells were also used to determine their selectivity toward cancer cells and normal cells, which showed that $18 \mathrm{~b}$ and $( \pm)-19 \mathrm{~b}$ selectively inhibited the growth of cancer cells.

The further in vitro assay for the inhibition of tubulin polymerization demonstrated that compounds $18 \mathrm{~b}$ and $( \pm)-19 \mathrm{~b}$ 
Table 1. Cytotoxicity against Five Cancer Cell Lines, Human Normal Hepatocyte LO2 Cells, and ITP of Compounds 18b, $( \pm)-19 \mathrm{~b},(R)-(+)-19 \mathrm{~b}$, and $(S)-(-)-19 \mathrm{~b}^{a}$

\begin{tabular}{|c|c|c|c|c|c|c|c|}
\hline \multirow[b]{2}{*}{ Compd. } & \multirow[b]{2}{*}{$\mathrm{KB}$} & \multicolumn{6}{|c|}{$\mathrm{IC}_{50}$ values $(\mu \mathrm{M})$} \\
\hline & & НCT-8 & MDA-MB-231 & K562 & $\mathrm{H} 22$ & $\mathrm{LO} 2$ & $\operatorname{ITP}^{b}$ \\
\hline $18 b$ & $0.016 \pm 0.002$ & $0.025 \pm 0.004$ & $0.028 \pm 0.004$ & $0.019 \pm 0.002$ & $0.010 \pm 0.001$ & $0.138 \pm 0.012$ & $4.2 \pm 0.3$ \\
\hline$( \pm)-19 b$ & $0.025 \pm 0.002$ & $0.030 \pm 0.002$ & $0.022 \pm 0.002$ & $0.010 \pm 0.001$ & $0.011 \pm 0.001$ & $0.095 \pm 0.010$ & $3.1 \pm 0.2$ \\
\hline$(R)-(+)-19 b$ & $0.012 \pm 0.002$ & $0.012 \pm 0.001$ & $0.011 \pm 0.002$ & $0.008 \pm 0.001$ & $0.008 \pm 0.002$ & $0.058 \pm 0.005$ & $2.5 \pm 0.1$ \\
\hline$(S)-(-)-19 b$ & $0.87 \pm 0.08$ & $0.94 \pm 0.12$ & $0.90 \pm 0.09$ & $0.46 \pm 0.06$ & $0.80 \pm 0.12$ & $0.90 \pm 0.08$ & $4.3 \pm 0.1$ \\
\hline CA-4 & $0.012 \pm 0.001$ & $0.015 \pm 0.002$ & $0.015 \pm 0.002$ & $0.015 \pm 0.002$ & $0.008 \pm 0.001$ & $0.095 \pm 0.002$ & $2.5 \pm 0.2$ \\
\hline 8 & $25.1 \pm 0.9$ & $35.2 \pm 1.3$ & $30.2 \pm 2.0$ & $20.5 \pm 1.2$ & $18.2 \pm 2.1$ & $22.2 \pm 1.2$ & $10.6 \pm 0.2$ \\
\hline
\end{tabular}

${ }^{a}$ MTT methods; cells were incubated with indicated compounds for $72 \mathrm{~h}$ (means $\pm \mathrm{SD}, n=3$ ). ${ }^{b}$ Inhibition of tubulin polymerization activity.

were potent inhibitors of tubulin polymerization. As shown in Table 1, compound $( \pm)-\mathbf{1 9 b}\left(\mathrm{IC}_{50}=3.1 \mu \mathrm{M}\right)$ was more potent than $18 \mathrm{~b}\left(\mathrm{IC}_{50}=4.2 \mu \mathrm{M}\right)$ and was slightly less potent than CA-4 $\left(\mathrm{IC}_{50}=2.5 \mu \mathrm{M}\right)$. Furthermore, $( \pm)$-19b exhibited nearly 3 -fold improvement of inhibitory activity of tubulin polymerization compared with $8\left(\mathrm{IC}_{50}=10.6 \mu \mathrm{M}\right)$, which suggested that the trimethoxyphenyl moiety has significant roles in binding with tubulin. In addition, in assay of the colchicine competitive experiment, the binding potency of $( \pm)-19 b$ to the colchicine binding site was comparable to that of CA-4 with the inhibition rates of $76.4 \%$ and $89.6 \%$ at $1 \mu \mathrm{M}$ and $5 \mu \mathrm{M}$, respectively (see Supporting Information Table S2), indicating that $( \pm)-19 b$ binds to the colchicine binding site.

Moreover, immunofluorescent assays were performed to investigate the effect of $( \pm)-19 b$ on microtubule networks. As shown in Figure 2, K562 cells exhibited normal filamentous microtubules

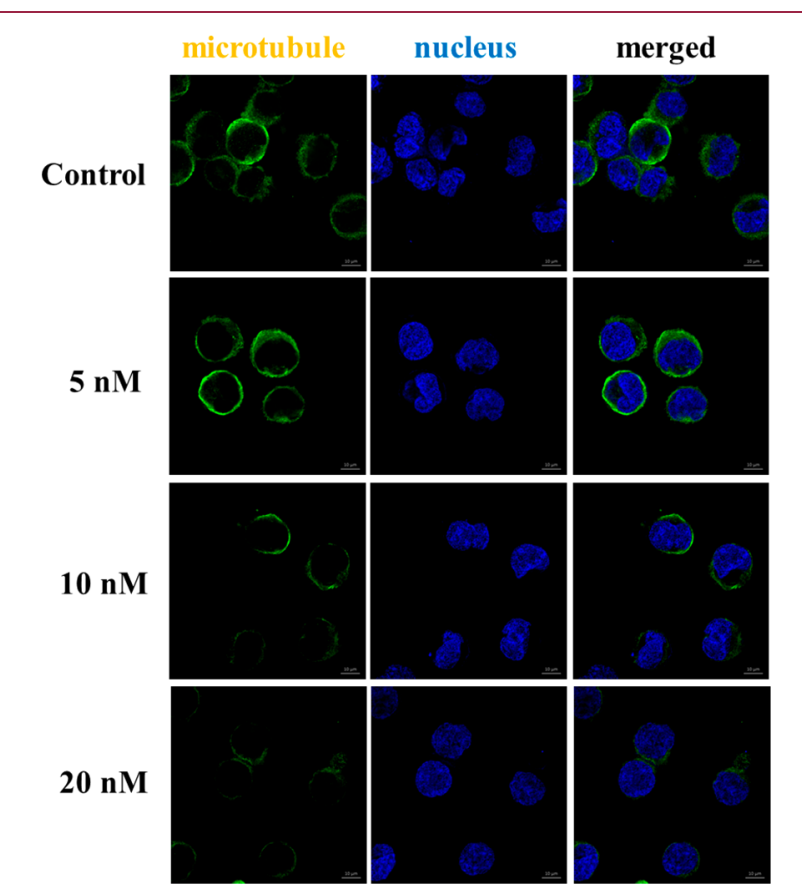

Figure 2. Effects of $( \pm)-19 b$ on the cellular microtubule network visualized by immunofluorescence.

arrays without drug treatment. However, after exposure to $( \pm)-19 b$ at three different concentrations (5 nM, $10 \mathrm{nM}$, $20 \mathrm{nM}$ ) for $24 \mathrm{~h}$, the microtubule networks in cytosol were disrupted, indicating that $( \pm)-19 b$ induced a dose-dependent collapse of the microtubule networks.

Since most microtubule polymerization inhibitors disrupt cell mitosis and exert cell cycle arrest effects, ${ }^{31}$ the effect of
$( \pm)-19 b$ on cell cycle progression using propidiumiodide (PI) staining in K562 cells was examined. When treated with ( \pm )-19b at $5 \mathrm{nM}, 10 \mathrm{nM}$, and $20 \mathrm{nM}$ for $48 \mathrm{~h}$, the percentages of cells arrested at the G2/M phase were $17.5 \%, 19.5 \%$, and $22.4 \%$, respectively, indicating that $( \pm)-19 b$ can disrupt the dynamic balance of the tubulin-microtubule system and further induced the cell cycle arrest at the G2/M phase (see Supporting Information Figure S1). Next, an Annexin V-APC/7-AAD binding assay was carried out to assess whether $( \pm)-19 b$ would induce cell apoptosis. The percentage of apoptotic cells after the $48 \mathrm{~h}$ treatment was only $5.7 \%$ in the control group. The total numbers of early (Annexin-V+/PI-) and late (Annexin-V+/PI+) apoptotic cells increased to $13.7 \%, 29.0 \%$, and $54.1 \%$ after treatment with $( \pm)-19 \mathrm{~b}$ at 5,10 , and $20 \mathrm{nM}$ for $48 \mathrm{~h}$, respectively (see Supporting Information Figure S2). These results confirmed that $( \pm)-\mathbf{1 9 b}$ effectively induced cell apoptosis in K562 cells in a dose-dependent manner.

In order to determine whether $( \pm)$-19b-induced apoptosis was involved in a disruption of mitochondrial membrane integrity, the fluorescent probe JC-1 was employed to measure the mitochondrial membrane potential (MMP). When treated with $( \pm)-19 b$ at concentrations of $0,5,10$, and $20 \mathrm{nM}$ for $48 \mathrm{~h}$, the number of K562 cells with collapsed MMP increased to $0.6 \%$, $12.7 \%, 26.7 \%$, and $55.1 \%$, respectively (see Supporting Information Figure S3), suggesting that $( \pm)-19 b$ caused mitochondrial depolarization of K562 cells in the process of apoptosis.

Most microtubule binding agents have antiangiogenic or vascular-disrupting activities or both, which are antivascular effects. ${ }^{32}$ Angiogenesis inhibiting agents (AIAs) interfere with new vessel formation, require chronic administration, and are likely to be of benefit in early stage or asymptomatic metastatic disease, while vascular-disrupting agents (VDAs) target the established tumor blood vessels, which are often given acutely and have particular efficacy against advanced disease. ${ }^{33}$ Considering that invasion and tube formation are highly relevant properties in the process of tumor vasculature, the HUVEC culture assay was used to assess the ability of $( \pm)-19 b$ to inhibit HUVEC migration. As a result, the untreated cells migrated to fill the area that was initially scraped after $24 \mathrm{~h}$. In contrast, $( \pm)-19 \mathrm{~b}$ significantly inhibited the HUVEC migration in a dose-dependent manner (see Supporting Information Figure S4A). Then we further evaluated the antivascular ability of $( \pm)-19 b$ in a tube formation assay. After being seeded on matrigel, HUVECs form the capillary-like tubules with multicentric junctions. After exposure to $( \pm)-19 \mathrm{~b}$ at doses of $0,5,10$, and $20 \mathrm{nM}$ for $6 \mathrm{~h}$, the capillary-like tubes were interrupted in different levels (Figure S4B). These results showed that $( \pm)-19 b$ effectively inhibited the tube formation of HUVECs.

Furthermore, we tested the in vivo antitumor activity of $( \pm)-19 b$ based on the in vitro antiproliferative activity and 
mechanistic studies. Mouse liver cancer xenograft model was established by subcutaneous inoculation of $\mathrm{H} 22$ cells into the right flank of mice. The tumor size and body weights of the mice were monitored and recorded every 2 days. Paclitaxel (PTX) was dosed as $8 \mathrm{mg} / \mathrm{kg}$ per 2 days (i.v.) due to its severe toxicity. To compare the antitumor efficacy of $( \pm)-19 b$ and CA-4, ( \pm )-19b and CA-4 were dosed at 15 and $30 \mathrm{mg} / \mathrm{kg}$ per day (i.v.). None of the mice died in all groups after 21 days treatments. As shown in Figure 3A, both $( \pm)-19 b$ at the dose

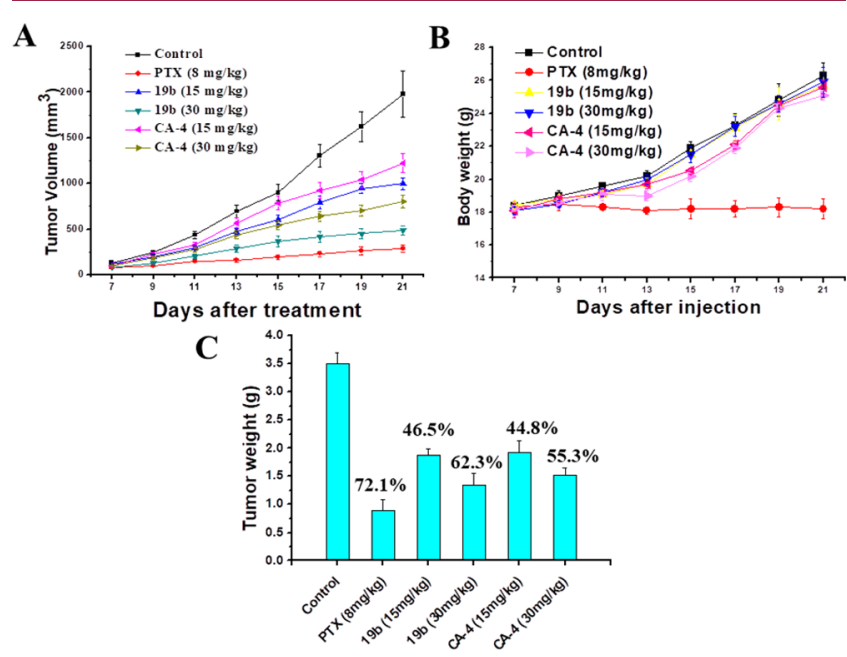

Figure 3. (A) Tumor growth curves after injection with different formulations in $\mathrm{H} 22$ tumor bearing mice. (B) Body weight changes of mice during treatment. (C) ( \pm )-19b treatment resulted in significantly lower tumor weight compared with controls.

of $30 \mathrm{mg} / \mathrm{kg}$ per day and PTX at the dose of $8 \mathrm{mg} / \mathrm{kg}$ per 2 days significantly decreased the tumor volume. The reduction in tumor weight of the PTX group reached $72.1 \%$ at 21 days after initiation of treatment as compared to vehicle, while $( \pm)-19 \mathrm{~b}$ reduced tumor weight by $46.5 \%$ and $62.3 \%$ at doses of 15 and $30 \mathrm{mg} / \mathrm{kg}$ per day (i.v.), respectively, which are more potent than CA- 4 treatment groups (inhibitory rates of $44.8 \%$ and $55.3 \%$ at doses of 15 and $30 \mathrm{mg} / \mathrm{kg}$ per day, respectively) (Figure 3C). Importantly, ( \pm )-19b did not significantly affect body weight even at the dose up to $30 \mathrm{mg} / \mathrm{kg}$, while treatment with PTX at a dose of $8 \mathrm{mg} / \mathrm{kg}$ per 2 days led to a significant decrease of body weight (Figure 3B). Thus, $( \pm)-19 b$ is worthy of further investigation for the treatment of cancers.

Finally, in order to investigate the effects of C-4 chirality on activity, the racemic mixture of $( \pm)-19 b$ was enantioseparated on a chiral column (see Supporting Information Figure S5) to afford (+)-19b and (-)-19b. Circular dichroism (CD) was performed to determine the absolute configuration, and the results indicated that the absolute configuration of $(+)-19 b$ is $R$-configured and the absolute configuration of $(-)-19 b$ is $S$-configured (see Supporting Information Figure S6).

Furthermore, $(R)-(+)-19 \mathrm{~b}$ and $(S)-(-)-19 \mathrm{~b}$ were evaluated for their antiproliferative and inhibitory activities of tubulin polymerization. As shown in Table 1, the R-configured 19b still exhibited very potent activity against five cancer cell lines, which were slightly more potent than $( \pm)-19 b$, whereas $(S)-(-)-19 b$ displayed a significant decrease of activity. As regards the antitubulin assays, $(R)-(+)-19 b \quad\left(\mathrm{IC}_{50}=\right.$ $2.5 \mu \mathrm{M})$ was about 2 -fold more potent than $(S)-(-)-19 \mathrm{~b}$ $\left(\mathrm{IC}_{50}=4.3 \mu \mathrm{M}\right)$. Moreover, in assay of the colchicine competitive experiment, the binding ability of $(R)-(+)-19 b$ to the colchicine binding site was more potent than $( \pm)-19 b$ and was comparable to that of CA-4 with the inhibition rates of $79.4 \%$ and $92.6 \%$ at $1 \mu \mathrm{M}$ and $5 \mu \mathrm{M}$ (Table S2).

To explain the significant difference in activity for two enantiomers of $( \pm)-19 b$, molecular modeling studies were performed by using the DOCK program in Discovery Studio 3.0 software with the tubulin crystal structure (PDB: 5lyj). As a result, $(R)-(+)-19 b$ adopted a very similar positioning with that of CA-4. The phenolic hydroxyl and 4-methoyl of (R)-(+)-19b and CA-4 formed hydrogen bonds with Thr179 and Cys241 residues, respectively. The oxygen atom in the isochromene ring interacted with residue Asn 258 by a weak hydrogen bond (see Supporting Information Figure S7A). However, the binding pose of $(S)-(-)-19 b$ was flipped over $180^{\circ}$ compared to that of CA-4, which may explain why both the antitubulin and antiproliferative activity of $(S)-(-)-19 b$ decreased dramatically (Figure S7B).

In summary, a series of novel 4-arylisochromenes have been synthesized based on the structure of XJP-L (8). Antiproliferative screening of these new synthesized compounds validated the representative compound $( \pm)-19 b$ as a high cytotoxic compound with $\mathrm{IC}_{50}$ ranging from 10 to $25 \mathrm{nM}$ against a panel of cancer cell lines, which displayed a 1000 -fold increase in activity compared with the lead 8 . It was found that $( \pm)-19 b$ also displayed potent inhibitory activity in tubulin polymerization assay $\left(\mathrm{IC}_{50}=3.1 \mu \mathrm{M}\right)$. Further mechanism studies demonstrated that $( \pm)-19 b$ caused cell cycle arrest in the G2/M phase, induced cell apoptosis, and depolarized mitochondria of K562 cells. And the immunofluorescent assay indicated that $( \pm)-19 b$ can effectively disrupt microtubule networks in a dose-dependent manner. The wound healing and tube formation assays also identified $( \pm)-19 b$ as a novel inhibitor of tubulin polymerization with potent vascular disrupting activity. Finally, the in vivo antitumor activity of ( \pm )-19b was validated in the H22 liver cancer xenograft mouse model, which is more potent than CA-4. Besides, $(\boldsymbol{R})$ $(+)-19 b$ and $(S)-(-)-19 b$ were obtained by chiral separation of $( \pm)-19 b$ and were evaluated for their antiproliferative and antitubulin activities, respectively. $(R)-(+)-19 b$ was slightly more potent than $( \pm)-19 b$ whereas $(S)-(-)-19 b$ displayed a significant decrease of activity, which was further elucidated by molecular modeling studies. Altogether, $( \pm)-19 b$ may represent a novel class of antitubulin agent with potent antivascular and antitumor activities and deserves further investigation.

\section{ASSOCIATED CONTENT}

\section{Supporting Information}

The Supporting Information is available free of charge on the ACS Publications website at DOI: 10.1021/acsmedchemlett.8b00217.

Synthetic methods and characterization of target compounds; procedures for pharmacological activities (PDF)

\section{AUTHOR INFORMATION}

\section{Corresponding Authors}

*E-mail address: cpuxst@163.com (S. Xu).

*E-mail address: cpu-jill@163.com (J. Liu).

*E-mail address: jinyixu@china.com (J. Xu). 


\section{ORCID}

Jinyi Xu: 0000-0002-1961-0402

\section{Notes}

The authors declare no competing financial interest.

\section{ACKNOWLEDGMENTS}

This study was supported by the National Natural Science Foundation of China (No. 81673306, 81703348), The Open Project of State Key Laboratory of Natural Medicines, China Pharmaceutical University (No. SKLNMKF 201710), and China Postdoctoral Science Foundation (No. 2017100424). The authors thank Dr. Dahong Li (Key Laboratory of Structure-Based Drug Design and Discovery of Ministry of Education and School of Traditional Chinese Materia Medica, Shenyang Pharmaceutical University, Shenyang, China) for the CD calculations.

\section{ABBREVIATIONS}

DMF, N, N-dimethylformamide; Xphos, 2-dicyclohexylphosphino-2', 4',6'-triisopropylbiphenyl; DCM, dichloromethane; THF, tetrahydrofuran; HUVECs, human umbilical vein endothelial cell

\section{REFERENCES}

(1) Pettit, G. R.; Singh, S. B.; Hamel, E.; Lin, C. M.; Alberts, D. S.; Garcia-Kendal, D. Isolation and structure of the strong cell growth and tubulin inhibitor combretastatin A-4. Experientia 1989, 45, 209211.

(2) Lin, C. M.; Singh, S. B.; Chu, P. S.; Dempcy, R. O.; Schmidt, J. M.; Pettit, G. R.; Hamel, E. Interactions of tubulin with potent natural and synthetic analogs of the antimitotic agent combretastatin: a structure-activity study. Mol. Pharmacol. 1988, 34, 200-208.

(3) Dark, G. G.; Hill, S. A.; Prise, V. E.; Tozer, G. M.; Pettit, G. R.; Chaplin, D. J. Combretastatin A-4, an agent that displays potent and selective toxicity toward tumor vasculature. Cancer Res. 1997, 57, $1829-1834$.

(4) Pérez-Pérez, M. J.; Priego, E. M.; Bueno, O.; Martins, M. S.; Canela, M. D.; Liekens, S. Blocking blood flow to solid tumors by destabilizing tubulin: An approach to targeting tumor growth. J. Med. Chem. 2016, 59, 8685-8711.

(5) Porcù, E.; Bortolozzi, R.; Basso, G.; Viola, G. Recent advances in vascular disrupting agents in cancer therapy. Future Med. Chem. 2014, 6, 1485-1498.

(6) Jaroch, K.; Karolak, M.; Górski, P.; Jaroch, A.; Krajewski, A.; Ilnicka, A.; Sloderbach, A.; Stefański, T.; Sobiak, S. Combretastatins: In vitro structure-activity relationship, mode of action and current clinical status. Pharmacol. Rep. 2016, 68, 1266-1275.

(7) Ji, Y.; Liu, Y.; Liu, Z. Tubulin colchicine binding site inhibitors as vascular disrupting agents in clinical developments. Curr. Med. Chem. 2015, 22, 1348-1360.

(8) https://www.clinicaltrials.gov/ (a) Focus: PCC + Bevacizumab + CA4P Versus PCC + Bevacizumab + Placebo for subjects with platinum resistant Ovarian Cancer; (b) Safety and effectiveness of Combretastatin A-4 phosphate combined with chemotherapy in advanced solid tumors; (c) Fosbretabulin or Placebo in combination with Carboplatin/Paclitaxel in Anaplastic Thyroid Cancer.

(9) http://investor.mateon.com/releasedetail.cfm?ReleaseID= 1041745.

(10) Aprile, S.; Del Grosso, E.; Tron, G. C.; Grosa, G. In vitro metabolism study of combretastatin A-4 in rat and human liver microsomes. Drug Metab. Dispos. 2007, 35, 2252-2261.

(11) Li, W.; Sun, H.; Xu, S.; Zhu, Z.; Xu, J. Tubulin inhibitors targeting the colchicine binding site: a perspective of privileged structures. Future Med. Chem. 2017, 9, 1765-1794.
(12) Kaur, R.; Kaur, G.; Gill, R. G.; Soni, R.; Bariwal, J. Recent developments in tubulin polymerization inhibitors: An overview. Eur. J. Med. Chem. 2014, 87, 89-124.

(13) Lu, Y.; Chen, J.; Xiao, M.; Li, W.; Miller, D. An overview of tubulin inhibitors that interact with the colchicine binding site. Pharm. Res. 2012, 29, 2943-2971.

(14) Sriram, M.; Hall, J. J.; Grohmann, N. C.; Strecker, T. E.; Wootton, T.; Franken, A.; Trawick, M. L.; Pinney, K. G. Design, synthesis and biological evaluation of dihydronaphthalene and benzosuberene analogs of the combretastatins as inhibitors of tubulin polymerization in cancer chemotherapy. Bioorg. Med. Chem. 2008, 16, 8161-8171.

(15) Herdman, C. A.; Strecker, T. E.; Tanpure, R. P.; Chen, Z.; Winters, A.; Gerberich, J.; Liu, L.; Hamel, E.; Mason, R. P.; Chaplin, D. J.; Trawick, M. L.; Pinney, K. G. Synthesis and biological evaluation of benzocyclooctene-based and indene-based anticancer agents that function as inhibitors of tubulin polymerization. MedChemComm 2016, 7, 2418-2427.

(16) Pinney, K. G.; Mocharla, V. P.; Chen, Z.; Garner, C. M.; Ghatak, A.; Hadimani, M.; Kessler, J.; Dorsey, J. M.; Edvardsen, K.; Chaplin, D. J.; Prezioso, J.; Ghatak, U. R. Tubulin binding agents and corresponding prodrug constructs. US20040043969-A1, 2004.

(17) Pinney, K. G.; Mocharla, V. P.; Chen, Z.; Garner, C. M.; Ghatak, A.; Hadimani, M.; Kessler, J.; Dorsey, J. M.; Edvardsen, K.; Chaplin, D. J.; Prezioso, J.; Ghatak, U. R. Tubulin binding agents and corresponding prodrug constructs: U.S. Patent 7001926, Feb 21, 2006.

(18) Devkota, L.; Lin, C.; Strecker, T. E.; Wang, Y.; Tidmore, J. K.; Chen, Z.; Guddneppanavar, R.; Jelinek, C. J.; Lopez, R.; Liu, L.; Hamel, E.; Mason, R.; Chaplin, D. J.; Trawick, M. L.; Pinney, K. G. Design, synthesis, and biological evaluation of water-soluble amino acid prodrug conjugates derived from combretastatin, dihydronaphthalene, and benzosuberene-based parent vascular disrupting agents. Bioorg. Med. Chem. 2016, 24, 938-956.

(19) Rasolofonjatovo, E.; Provot, O.; Hamze, A.; Rodrigo, J.; Bignon, J.; Wdzieczak-Bakala, J.; Desravines, D.; Dubois, J.; Brion, J.; Alami, M. Conformationnally restricted naphthalene derivatives type isocombretastatin A-4 and isoerianin analogues: synthesis, cytotoxicity and antitubulin activity. Eur. J. Med. Chem. 2012, 52, 22-32.

(20) Yan, J.; Hu, J.; An, B.; Huang, L.; Li, X. Design, synthesis, and biological evaluation of cyclic-indole derivatives as antitumor agents via the inhibition of tubulin polymerization. Eur. J. Med. Chem. 2017, $125,663-675$.

(21) Galli, U.; Travelli, C.; Aprile, S.; Arrigoni, E.; Torretta, S.; Grosa, G.; Massarotti, A.; Sorba, G.; Canonico, P. L.; Genazzani, A. A.; Tron, G. C. Design, synthesis, and biological evaluation of combretabenzodiazepines: a novel class of anti-tubulin agents. J. Med. Chem. 2015, 58, 1345-1357.

(22) Yao, H.; Liu, J.; Xu, S.; Zhu, Z.; Xu, J. The structural modification of natural products for novel drug discovery. Expert Opin. Drug Discovery 2017, 12, 121-140.

(23) Qian, H.; Huang, W. L.; Wu, X. M.; Zhang, H. B.; Zhou, J. P.; Ye, W. C. A new isochroman-4-one derivative from the peel of Musa sapientum L. and its total synthesis. Chin. Chem. Lett. 2007, 18, $1227-1230$

(24) Liu, J.; Ren, H.; Xu, J.; Bai, R.; Yan, Q.; Huang, W.; Wu, X.; Fu, J.; Wang, Q.; Wu, Q.; Fu, R. Total synthesis and antihypertensive activity of $( \pm)$ 7, 8-dihydroxy-3-methyl-isochro- -man-4-one. Bioorg. Med. Chem. Lett. 2009, 19, 1822-1824.

(25) Fu, R.; Chen, Z.; Wang, Q.; Guo, Q.; Xu, J.; Wu, X. XJP-1, a novel ACEI, with anti-inflammatory properties in HUVECs. Atherosclerosis 2011, 219, 40-48.

(26) $\mathrm{Fu}, \mathrm{R}$; Wang, Q.; Guo, Q.; Xu, J.; Wu, X. XJP-1 protects endothelial cells from oxidized low-density lipoprotein-induced apoptosis by inhibiting NADPH oxidase subunit expression and modulating the PI3K/Akt/eNOS pathway. Vasc. Pharmacol. 2013, 58, $78-86$.

(27) Negi, A. S.; Gautam, Y.; Alam, S.; Chanda, D.; Luqman, S.; Sarkar, J.; Khan, F.; Konwar, R. Natural antitubulin agents: 
Importance of 3,4,5-trimethoxyphenyl fragment. Bioorg. Med. Chem.

2015, 23, 373-3891.

(28) Dong, M.; Liu, F.; Zhou, H.; Zhai, S.; Yan, B. Novel natural product and privileged scaffold-based tubulin inhibitors targeting the colchicine binding site. Molecules 2016, 21, 1375.

(29) Li, L.; Jiang, S.; Li, X.; Liu, Y.; Su, J.; Chen, J. Recent advances in trimethoxyphenyl (TMP) based tubulin inhibitors targeting the colchicine binding site. Eur. J. Med. Chem. 2018, 151, 482-494.

(30) Wang, C.; Wu, Z.; Wang, J.; Liu, J.; Yao, H.; Lin, A.; Xu, J. An efficient synthesis of 4-isochromanones via parham-type cyclization with weinreb amide. Tetrahedron 2015, 71, 8172-8177.

(31) Dumontet, C.; Jordan, M. A. Microtubule-binding agents: a dynamic field of cancer therapeutics. Nat. Rev. Drug Discovery 2010, 9, 790-803.

(32) Schwartz, E. L. Antivascular actions of microtubule-binding drugs. Clin. Cancer Res. 2009, 15, 2594-2601.

(33) Siemann, D. W.; Bibby, M. C.; Dark, G. G.; Dicker, A. P.; Eskens, F. A.L.M.; Horsman, M. R.; Marme, D.; LoRusso, P. M. Differentiation and definition of vascular-targeted therapies. Clin. Cancer Res. 2005, 11, 416-420. 